\title{
The Role of Entrepreneurial Self-Efficacy and Entrepreneurial Passion in Firm Performance
}

\author{
Nattanan Saksamrit ${ }^{1}$, Kullanun Sripongpun*2 \\ ${ }^{1,2}$ Kasetsart University, Sakonnakhon, Thailand
}

\begin{abstract}
Objective - This research clarifies how entrepreneurial self-efficacy (ESE) affects performance, and entrepreneurial passion (EP) may vary the ESE- firm performance relationship as a mediator.

Methodology/Technique - The data was collected using a questionnaire distributed to 400 entrepreneurs in Sakon Nakhon, Nakhon Phanom, and Mukdahan Province, Thailand. All measures had acceptable Cronbach's alpha reliabilities. Descriptive statistics, mean, and standard deviation were used to analyze the data. The conceptual model and hypotheses were tested by using linear regression analysis. Confirmatory factor analysis was used to test construct validity.

Finding - The results show that the entrepreneurial self-efficacy had no effect of multicollinearity in the independent variables (Hair et. al., 2014). Therefore, it was possible to test the equation analysis based on the hypothesis using linear regression. In terms of direct relationship testing, entrepreneurial self-efficacy directly had a significant positive impact on firm performance and passion. In addition, entrepreneurial passion directly influenced firm performance. In terms of indirect relationship testing, entrepreneurial passion is a partial mediation for entrepreneurial self-efficacy and firm performance.

Novelty - This paper examines how self-efficacy (ESE) affects firm performance and how self-efficacy (ESE) affects firm performance when mediated by passion. This study may provide for higher accomplishment and greater performance.
\end{abstract}

Type of Paper: Empirical.

JEL Classification: M10, M12.

Keywords: Entrepreneurial Self-Efficacy; Entrepreneurial Passion; Firm Performance

Reference to this paper should be made as follows: Saksamrit, N; Sripongpun, K. (2021). The Role of Entrepreneurial Self-Efficacy and Entrepreneurial Passion in Firm Performance, GATR Global J. Bus. Soc. Sci. Review, 9(1): 33 - 40. https://doi.org/10.35609/gjbssr.2021.9.1(4)

\section{Introduction}

Small and medium enterprises are considered a significant drive for innovation, economic growth, competitiveness and prosperity (Office of Small and Medium Enterprise Promotion, 2014).

\footnotetext{
${ }^{*}$ Paper Info: Revised: December 19, 2020

Accepted: March 31, 2021

* Corresponding author: Kullanun Sripongpun

E-mail: kullanun.s@ku.th

Affiliation: Kasetsart University, Sakonnakhon, Thailand
} 
The field of entrepreneurship represents an increasingly dynamic productive force in the economy (Gavron et. al., 1998). Business creates new job and increases welfare and society values, which leads to economic growth and prosperity. In 2014, Thailand had a total of 2,736,744 SMEs accounting for 99.7\% of all enterprises in the country. Thai SMEs generated employment of 10,501,166 people accounting for $80.3 \%$ of all employment and created value for the gross product in gross domestic product (GDP) at 5,212,004million-baht accounting for $39.6 \%$ of GDP. Despite the large numbers of SMEs, most of them are small enterprises. The proportion of medium enterprise is only at $0.5 \%$ of all SMEs while the proportion of medium-sized enterprises is at 5-10\% in developed countries. This reflects the many limitations discouraging development from small enterprises to medium enterprises such as management knowledge, management capability, sufficient capital gathering or effective employee maintenance. A small number of medium enterprises referred to as the 'missing middle' present an obstacle of economic growth and innovation (Office of Small and Medium Enterprise Promotion, 2014). To achieve greater performance of enterprises in countries, focus should be directed on the development and encouragement of entrepreneurship.

Performance achievement is a result of great motivation, ability, and chance. In contrast, higher performance leads to competitive advantage. Therefore, it is vital to clarify factors influencing firm performance. Among the various factors affecting the performance of all businesses, self-efficacy is the most important factor leading to performance accomplishment. Based on Bandura's social learning theory, selfefficacy is one's belief in his or her ability to succeed various goals and tasks in their life (Miao et. al., 2017). Self -efficacy is described as beliefs that influences how people think, feel and behave when they face different situations. Many studies have shown positive relationships between entrepreneurial self-efficacy (ESE) and entrepreneurial intentions, and between entrepreneurial self-efficacy (ESE) and business startup. In addition, several studies have suggested that entrepreneurial self-efficacy (ESE) is expected to contribute to high performance. On the contrary, there are some ambiguities in the relationship between entrepreneurial self-efficacy (ESE) and firm performance and the influence of entrepreneurial self-efficacy (ESE) and firm performance, indicating both weak and strong relationships.

In addition, another factor affecting to firm performance is passion. Passion is described as any strong emotion or desire. Passion is considered as an entrepreneurial effort determinant because it is able to bring up creativity and take advantage from encouraging opportunities (Baron, 2008; Cardon et. al. 2013). However, there is little research focusing on entrepreneurial passion (EP) leading to firm performance (Cardon et. al. 2013). Thus, this research aims to clarify how entrepreneurial self-efficacy (ESE) affects firm performance, and entrepreneurial passion (EP) may vary the ESE- firm performance relationship as a mediator.

\section{Literature Review}

\subsection{Firm Performance}

Performance is the end result of activities. Performance can be assessed in terms of time, money, resource use and so on. Therefore, entrepreneurs must focus on firm performance being the final cumulative outcome of all tasks and all activities such as profit, sales, customer satisfaction and productivity. In various organizations, performance reflects the efficiency and effectiveness in using organizational resources to achieve organizational goals and create customer satisfaction. The concept of efficiency and effectiveness cannot only be used to measure the success of the management, but also have an impact on an organization's competitive advantage. Firm performance refers to supporting firm goals, finding market opportunities, seeking customer needs, developing new products, creating suitable environments and policies, developing investor relationships, being prompt to react on irregular situations affecting to business and maximizing income and profit (DeNoble, Jung, Ehrlich, 1999).

The general measurements of firm performance include financial and marketing measurements from data such as revenue, profit, return on asset, and customer satisfaction (Richard et. al., 2009). Robert Kaplan and David Norton presented the Balance Scorecard (BSC) as a tool for measuring firm performance. The Balance

GATR Global J. Bus. Soc. Sci. Review 9 (1) 33 - 40 (2021) 
Scorecard (BSC) is a firm performance indicator translated from firm mission and strategy and divided into 2 aspects: financial and non-financial performance indicators. Ndubisi (2013) describes performance measurements in 3 ways: 1) financial performance measurement consists of ROA, ROI, gross margin and profitability, 2) marketing performance measurement includes market share, sales volume, sales growth and new product launching, 3) other indicators are overall customer satisfaction, overall organizational performance, and the achievement of strategic objectives.

\subsection{Entrepreneurial Self-efficacy (ESE)}

According to Albert Bandura's social learning theory, self-efficacy is defined as the belief of a person that they can handle tasks successfully. A high level of self-efficacy beyond actual ability leads to overestimation of potential to achieve tasks. On the other hand, low self-efficacy is an obstacle of confidence and development. Self-efficacy composes of strength and generality of person's belief in their own ability to accomplish tasks. High self-efficacy leads to perception that the task being completed is easier than they actually are. Entrepreneurs holding entrepreneurial self-efficacy (ESE) have strong beliefs in their own abilities to accomplish entrepreneurial tasks including setting challenging goals, showing persistence, putting strong effort, facing challenges competently and quick recovering from failure (Bandura, 1986; Lindsley, Brass, and Thomas, 1995). Therefore, entrepreneurs with a sense of entrepreneurial self-efficacy (ESE) are likely to exert a higher level of effort in their responsibilities. Entrepreneurial self-efficacy (ESE) comprises 5 dimensions: marketing, innovation, risk-taking, management and financial control (Klongthong et. al., 2020). In addition, there are various studies supporting the positive relationship between self-efficacy (ESE) and work performance. Many studies conclude that entrepreneurial self-efficacy (ESE) is positively related to firm performance of new ventures and entrepreneurial self-efficacy (ESE) is directly related to firm performance in term of financial and marketing dimensions (Forbes, 2005 \& Klongthong et. al., 2020). However, some studies describe that this relationship varies on task complexity. The easier the task, the stronger relationship between self-efficacy and work performance. In conclusion, entrepreneurial selfefficacy (ESE) is considered a motive to transform entrepreneurs' perceptions into strong effort and higher performance. Therefore, we hypothesize that:

Hypothesis 1: Entrepreneurial self-efficacy (ESE) has a positive relationship with firm performance.

\subsection{Entrepreneurial Passion}

Passion is a main determinant of entrepreneurship (Cardon et. al, 2010). Generally, entrepreneurial passion creates a distinctive emotion in entrepreneurs (Cardon et. al., 2013). Cardon et. al. (2009) state that a person with entrepreneurial passion shows a good sense of entrepreneurial activities and has motivational drive to fulfill tasks. Passion involves a desire and effort in starting up businesses. It is a crucial drive of performance success in launching new products and services and founding firms (Cardon et. al, 2013). It is also the ability to "fuel motivation, enhance mental activity, and provide meaning to everyday work" (Brannback et. al., 2006). Moreover, entrepreneurial passion persuades to collect investor funding (Cardon et. al., 2009; Mitteness et. al., 2012), to recruit and retain talented employees, and to gather social resources (Cardon et. al., 2009; Chen et. al., 2009). There are findings that firm innovation and market share vary on strength of entrepreneurial passion feeling (Mitchell \& Randolph-Seng, 2014) Accordingly, various studies consider that entrepreneurial passion has 3 dimensions- entrepreneurial investing, founding and developing desire. Therefore, to understand the factors that affect performance clearly, we need to consider entrepreneurial passion along with entrepreneurial self-efficacy and performance. Thus, we hypothesize that:

Hypothesis 2: Entrepreneurial self-efficacy (ESE) has a positive relationship with firm performance when mediated by entrepreneurial passion (EP). 


\section{Research Methodology}

This study is a quantitative research. The sampling procedure involved entrepreneurs in Sakon Nakhon, Nakhon Phanom, and Mukdahan Province, Thailand. A sample of 400 entrepreneurs was initially drawn from the database. The data was collected using a questionnaire. The data was collected through the following 3 parts of the questionnaire.

Entrepreneurial Self-efficacy. To investigate entrepreneurial self-efficacy, a five-scale questionnaire was developed. The respondents considered their self-efficacy as entrepreneurs such as finding business opportunities, founding a business, launching new products and services to the market, creating revenue from products and services, recruiting talented employees, and successfully managing business finance. Entrepreneurial Passion. The questions were designed based on Cordon's study. The questions were divided into 3 parts: entrepreneurial investing, founding and developing passion.

Firm Performance. Financial and marketing questions were used to determine the firm performance of the respondents.

Cronbach's alpha coefficient was calculated in the questionnaire. Cronbach's alpha coefficient was 0.854 and 0.875 . Descriptive statistics, mean, and standard deviation were used to analyze the data. Linear regression analysis was used to test the conceptual model and hypotheses. Construct validity was tested by using confirmatory factor analysis. All variables were loaded into 1 component indicating that it was constructed with validity.

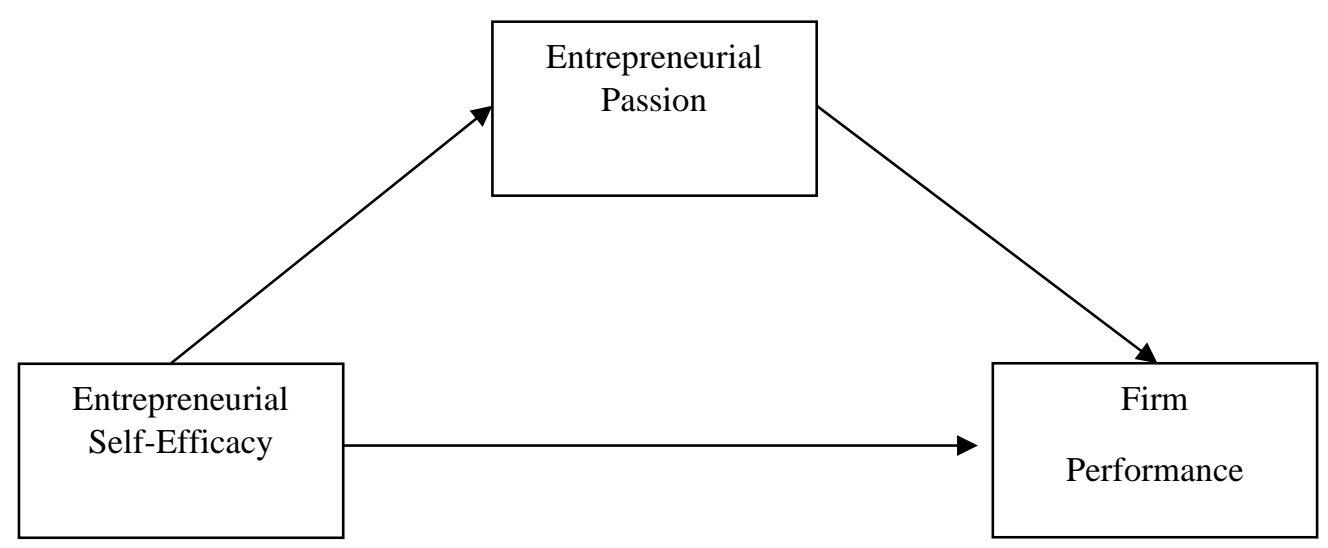

Figure 1. Conceptual Model

\section{Results}

Linear regression analysis was used to examine the conceptual model and hypotheses as Baron and Kenny's (1986) procedure.

Table 1. Mean, standard deviation and correlation

\begin{tabular}{|c|c|c|c|}
\hline & Self-efficacy & Performance & Passion \\
\hline MEAN & 3.89 & 3.42 & 3.99 \\
\hline S.D. & 0.70 & 0.90 & 0.63 \\
\hline Self-efficacy & 1.000 & & \\
\hline Performance & $0.532^{* *}$ & 1.000 & \\
\hline & & & \\
\hline Passion & $0.759 * *$ & $0.538^{* *}$ & 1.000 \\
\hline
\end{tabular}


The results indicate that the mean of entrepreneurial passion (EP) was the highest at 3.99 and the mean of entrepreneurial self- efficacy (ESE) and performance were 3.89 and 3.42 respectively. Additionally, Table 1 presents the relationship between the dependent variable and independent variable. Pearson's correlation analysis was used to examine the relationship of the independent variables. The results show that the relationship between the independent variables are $0.532,0.759$ and 0.538 being lower than 0.80 . It therefore has no effects on multicollinearity among the independent variables (Hair et. al., 2014). Therefore, it was possible to test the equation analysis based on the hypothesis using linear regression.

Table 2. Simple regression analysis

\begin{tabular}{|c|c|c|c|c|c|c|c|}
\hline \multirow[t]{2}{*}{$\begin{array}{l}\text { Independent } \\
\rightarrow \text { Dependent }\end{array}$} & \multicolumn{2}{|c|}{$\begin{array}{l}\text { Unstandardized } \\
\text { Coefficients }\end{array}$} & \multirow[t]{2}{*}{ R2 } & \multirow[t]{2}{*}{ S.E.E } & \multirow[t]{2}{*}{$\mathrm{F}$} & \multirow[t]{2}{*}{$\mathrm{t}$} & \multirow[t]{2}{*}{ Sig. } \\
\hline & B & $\begin{array}{l}\text { Std. } \\
\text { Error }\end{array}$ & & & & & \\
\hline $\begin{array}{l}\text { Self-efficacy } \rightarrow \\
\text { Performance }\end{array}$ & 0.748 & 0.043 & 0.434 & 0.602 & 305.64 & 17.483 & $0.000 *$ \\
\hline $\begin{array}{l}\text { Self-efficacy } \rightarrow \\
\quad \text { Passion }\end{array}$ & 0.678 & 0.29 & 0.577 & 0.409 & 541.83 & 23.277 & $0.000 *$ \\
\hline $\begin{array}{c}\text { Passion } \rightarrow \\
\text { Performance }\end{array}$ & 0.768 & 0.60 & 0.289 & 0.757 & 162.05 & 12.730 & $0.000 *$ \\
\hline $\begin{array}{l}\text { Self-efficacy } \rightarrow \\
\text { Performance }\end{array}$ & 0.371 & 0.081 & 0.325 & 0.546 & 95.67 & 4.5939 & $0.000 *$ \\
\hline $\begin{array}{l}\text { Passion } \rightarrow \\
\text { Performance }\end{array}$ & 0.453 & 0.091 & & & & 5.003 & $0.000 *$ \\
\hline
\end{tabular}

Simple regression was used to test the hypothesis. The results of the hypothesis testing reveal that in terms of direct relationship testing, entrepreneurial self-efficacy (ESE) directly had a significant and positive impact on firm performance and entrepreneurial passion (EP) at 0.748 and 0.678 respectively with the statistical significance at 0.05 . The R2 were 0.434 and 0.577 . This shows that entrepreneurial self- efficacy (ESE) could predict firm performance and entrepreneurial passion (EP) of $43.4 \%$ and $57.7 \%$ respectively. In addition, entrepreneurial passion (EP) had a direct influence on firm performance at 0.768 with the statistical significance at 0.05 and had the ability to predict the dependent variables by $28.9 \%$. In terms of indirect relationship testing by using multiple regression, with the addition of entrepreneurial passion (EP) as a mediator, the effect of entrepreneurial self-efficacy (ESE) on firm performance was reduced from 0.748 to 0.371 at 0.05 level of significance. The R2 was 0.325 . This shows that $32.5 \%$ of variance in entrepreneurial self-efficacy (ESE) and entrepreneurial passion (EP) could predict firm performance. Standardized coefficients $(\beta)$ of entrepreneurial self- efficacy (ESE) and firm performance were reduced by adding entrepreneurial passion (EP) as a mediator. This indicates that entrepreneurial passion (EP) was probably a partial mediator between entrepreneurial self-efficacy (ESE) and firm performance relationship. Thus, direct and indirect effects were tested to calculate VAF, which can indicate whether entrepreneurial passion (EP) was an actual partial mediator between entrepreneurial self-efficacy (ESE) and firm performance relationship. The results of direct and indirect effects testing were in Table 3 below. 
Table 3. Direct indirect effect

\begin{tabular}{|c|c|c|c|c|}
\hline & \multicolumn{2}{|c|}{$\begin{array}{c}\text { Unstandardized } \\
\text { Coefficients }\end{array}$} & t & Sig. \\
\cline { 2 - 3 } & $\mathrm{B}$ & $\begin{array}{c}\text { Std. } \\
\text { Error }\end{array}$ & & \\
\hline Total effect & 0.678 & .054 & 12.524 & $0.000^{*}$ \\
\hline Direct effect & 0.371 & 0.081 & 4.594 & $0.000^{*}$ \\
\hline $\begin{array}{c}\text { Indirect effect) s) } \\
\text { Passion }\end{array}$ & 0.307 & & & \\
\hline
\end{tabular}

To determine whether entrepreneurial passion (EP) was a mediating variable, we examined 1) whether the total effect was higher than 0.2, meaning that the influence of the intermediate variable in the equation (Chin, 1998), 2) whether the indirect influence was significant, indicating that entrepreneurial passion (EP) was a mediating variable and 3 ) whether the direct effect was reduced to 0 , meaning that that mediating variable was not necessary in this equation. If VAF was greater than 0.8 , then entrepreneurial passion (EP) was a full mediate variable. If the direct effect was not 0 but significant, and VAF was between 0.2-0.8, indicating that entrepreneurial passion (EP) was a partial mediate variable. There are also variables that are partial mediate (Hair et. al., 2014).

The results in Table 3 indicate that 1) the total effect value from the entrepreneurial self-efficacy (ESE) variables to the firm performance variables was 0.678 being higher than 0.2 . This indicated that there was an influence of the mediator in the equation (Chin, 1998). 2) The indirect effect was 0.307 with the statistical significance at 0.05 . This indicates that entrepreneurial passion (EP) was a mediating variable. 3) The direct influence of entrepreneurial self-efficacy (ESE) on firm performance was decreased from 0.748 to 0.371 , meaning that there was a mediating variable. As the result of VAF (variable account for) testing, the VAF was $0.307 / 0.678=0.453$ which was between 0.20 and 0.80 (Hair et. al., 2014). Thus, entrepreneurial passion (EP) was probably a partial mediator between entrepreneurial self-efficacy (ESE) and firm performance. Presumably, there are also other variables being partial mediate of the relationship between entrepreneurial self-efficacy (ESE) and firm performance, which will be further examined in the future.

\section{Discussion}

As a result of investigating the influence of entrepreneurial self-efficacy (ESE) on firm performance, we identified the relations between entrepreneurial self-efficacy (ESE) and firm performance at 0.748 . This result supports the social learning theory that self-efficacy (ESE) is positively relate to firm performance. Our findings are also consistent with the previous study conducted by Miao et. al. (2017) which discussed the positive relationship between entrepreneurial self-efficacy (ESE) and firm performance and Klongthong et. al. (2020) identified that self-efficacy (ESE) and innovation has a positive influence on startup performance in term of financial and customer satisfaction. Furthermore, the results of this study are congruent with the findings of Sidiqui's (2016) study suggesting that passion derived entrepreneurial self-efficacy (ESE) and improved individual performance.

In addition, we examine the relationship between entrepreneurial self-efficacy (ESE) and firm performance with entrepreneurial passion (EP) as mediator. The findings show that entrepreneurial passion was a partial mediator between entrepreneurial self-efficacy (ESE) and firm performance. This investigation supports Sidiqui's (2016) study which found that the effects of founding passion reduced entrepreneurial selfefficacy (ESE) to firm performance relationship, while the effect of developing passion was not significant. 


\section{Conclusion}

This research investigated the direct relationship between entrepreneurial self-efficacy (ESE) and firm performance. Additionally, this research examined the relationship between entrepreneurial self-efficacy (ESE) and firm performance when mediated by entrepreneurial passion (EP) in aspects of investing, developing, and founding business among SMEs in Sakon Nakhon, Nakhon Phanom, and Mukdahan Provinces, Thailand.

The research illustrates that entrepreneurial self-efficacy (ESE) has a significant positive impact on firm performance. Partially, entrepreneurial passion (EP) mediates the effect of entrepreneurial self-efficacy (ESE) on firm performance. Entrepreneurial passion (EP) is obtained from entrepreneurial self-efficacy (ESE) and enhances firm performance. In conclusion, entrepreneurs have more entrepreneurial passion (EP) when they have self-confidence in their own business. Consequently, running businesses with strong sense of self-efficacy and passion is a crucial factor to achieving higher performance.

This research provides a clearer understanding that entrepreneurial self-efficacy (ESE) and entrepreneurial passion (EP) help improve firm performance. Entrepreneur then should be confident to operate their businesses and strengthen their passion for investing, developing and founding business. Further research may consider other factors that may influence entrepreneurial self-efficacy (ESE)- firm performance relationship such as entrepreneurial experience and contextual factors (firm age, cultural values, and creativity).

\section{Acknowledgements}

This study was supported by Faculty of Liberal Art and Management Science, Kasetsart University Chalermphrakiat Sakon Nakhon Province Campus.

\section{References}

Bandura, A. (1990). Perceived self-efficacy in the exercise of personal agency. Journal of applied sport psychology, 2(2), 128-163. DOI: https://doi.org/ 10.1080/10413209008406426

Bandura, A., \& Schunk, D. H. (1981). Cultivating competence, self-efficacy, and intrinsic interest through proximal self-motivation. Journal of personality and social psychology, 41(3), 586. https://doi.org/10.1037/0022-3514.41.3.586

Bandura, A. (1986). Social foundations of thought and action. Englewood Cliffs, NJ, 1986(23-28). DOI: 10.5465/amr.2008.31193166.

Baron, R. M., \& Kenny, D. A. (1986). The moderator-mediator variable distinction in social psychological research: Conceptual, strategic, and statistical considerations. Journal of personality and social psychology, 51(6), 1173.

Birch, D. G. (1987). Job creation in America: How our smallest companies put the most people to work. University of Illinois at Urbana-Champaign's Academy for Entrepreneurial Leadership Historical Research Reference in Entrepreneurship.

Cardon, M. S., Sudek, R., \& Mitteness, C. (2009). The impact of perceived entrepreneurial passion on angel investing. Frontiers of entrepreneurship research, 29(2), 1. DOI: 10.5465/AMBPP.2009.44244277

Cardon, M. S., Wincent, J., Singh, J., \& Drnovsek, M. (2009). The nature and experience of entrepreneurial passion. Academy of management Review, 34(3), 511-532. DOI: 10.5465/AMBPP.2009.40633190

Cardon, M. S., \& Kirk, C. (2010). Passion, self-efficacy, and persistence in entrepreneurship. In Academy of Management Conference, Montreal, Canada.

Cardon, M. S., Gregoire, D. A., Stevens, C. E., \& Patel, P. C. (2013). Measuring entrepreneurial passion: Conceptual foundations and scale validation. Journal of business venturing, 28(3), 373-396. DOI: https://doi.org/ 10.1016/j.jbusvent.2012.03.003

Chen, X. P., Yao, X., \& Kotha, S. (2009). Entrepreneur passion and preparedness in business plan presentations: a persuasion analysis of venture capitalists' funding decisions. Academy of Management journal, 52(1), $199-214$. https://doi.org/10.5465/amr.2009.36462018. 
Chin, W. W. (1998). The partial least squares approach to structural equation modeling. Modern methods for business research, 295(2), 295-336. https://psycnet.apa.org/record/1998-07269-010

Drnovšek, M., Slavec, A., and Cardon, M.S. (2014). Cultural context, passion and self-efficacy: Do entrepreneurs operate on different 'planets'?. Handbook of Entrepreneurial Cognition. Edward Elgar Publishing Ltd. Drnovšek, M., Slavec, A., \& Cardon, M. S. (2014). Cultural context, passion and self-efficacy: do entrepreneurs operate on different 'planets'?. In Handbook of Entrepreneurial Cognition. Edward Elgar Publishing. DOI:https://doi.org/10.4337/9781781006597.00017

DeNoble A., Jung D., \& Ehrlich S. (1999). Entrepreneurial self-efficacy: The development of a measure and its relationship to entrepreneurial action. In Reynolds RD, Bygrave WD, Manigart S, Mason CM (Eds), Frontiers of entrepreneurship Research. Walham, MA: P\&R Publications. 73-78.

https://fusionmx.babson.edu/entrep/fer/papers99/I/I_C/IC.html

Forbes, D. P. (2005). The effects of strategic decision making on entrepreneurial self-efficacy. Entrepreneurship theory and practice, 29(5), 599-626. https://doi.org/10.1111/j.1540-6520.2005.00100.x

Gavron, R. (1998). The entrepreneurial society. Institute for Public Policy Research.

Hair, J. F. Jr, W. C. Black, B. J. Babin and R. E. Anderson. (2014). Multivariate Data Analysis, 7th ed. Harlow: Pearson Education Limited. Hair, J. F., Black, W. C., Babin, B. J., Anderson, R. E., \& Tatham, R. L. (2014). Pearson new international edition. In Multivariate data analysis, Seventh Edition. Pearson Education Limited Harlow, Essex.

Klongthong, W, Thavorn, J., Thanabodypath, W., Dhammathattariya, P., \& Chandrachai, A. (2020). The influence of entrepreneurial self-efficacy and innovation on firm performance: evidence from thai startup firms. Humanities and Social Sciences Letters, 8 (4), 450-463. DOI: 10.18488/jornal.73.2020.84.450.463.

Lindsley, D. H., Brass, D. J., \& Thomas, J. B. (1995). Efficacy-performing spirals: A multilevel perspective. Academy of management review, 20(3), 645-678. https://doi.org/10.5465/amr.1995.9508080333

Miao, C., Qian, S., \& Ma, D. (2017). The relationship between entrepreneurial self-efficacy and firm performance: a meta-analysis of main and moderator effects. Journal of Small Business Management, 55(1), 87-107. DOI: $10.1111 /$ jsbm. 12240

Randolph-Seng, B., Mitchell, R. K., Vahidnia, H., Mitchell, J. R., Chen, S., \& Statzer, J. (2015). The microfoundations of entrepreneurial cognition research: toward an integrative approach. Now. DOI: 10.1561/0300000055.

Mitteness, C., Sudek, R., \& Cardon, M. S. (2012). Angel investor characteristics that determine whether perceived passion leads to higher evaluations of funding potential. Journal of Business Venturing, 27(5), 592-606. DOI: 10.111/etap. 12255

Ndubisi, N. O., \& Iftikhar, K. (2012). Relationship between entrepreneurship, innovation and performance. Journal of Research in Marketing and entrepreneurship. https://doi.org/ 10.1108/14715201211271429.

Office of Small and Medium Enterprise Promotion. (2014). Get to know Thai SMEs. https://www.sme.go.th

Richard, P. J., Devinney, T. M., Yip, G. S., \& Johnson, G. (2009). Measuring organizational performance: Towards methodological best practice. Journal of management, 35(3), 718-804. DOI: https://doi.org/10.1177/0149206308330560 Siddiqui, M. (2016). Entrepreneurial Passion as Mediator of the Entrepreneurial Self Efficacy and Entrepreneurial Performance, Relationship: An Empirical Study in Small Medium Businesses. Journal of Entrepreneurship \& Organization Management, 5(3), 1-7.DOI: 10.4172/2169-026x.1000200. 